\title{
Surgical results of remnant gastric cancer treatment
}

\section{Resultados cirúrgicos do tratamento dos tumores do coto gástrico}

Marcus Fernando Kodama Pertille Ramos, TCBC-SP1 1 i ; Maria Claudia Machado Pereira ${ }^{2}$; Yara Souza Oliveira ${ }^{2}$; Marina Alessandra Pereira'; 'Leandro Cardoso Barchi, TCBC-SP1; Andre Roncon Dias ${ }^{1}$; Bruno Zllberstein, ECBC-SP1; Ulysses Ribeiro JUNIOR, TCBC-SP'; IVAN CECCONELLO, ECBC-SP'1.

\section{A B S T R A C T}

\begin{abstract}
Background: remnant gastric cancer (RGC) develops five years or later after previous resection for benign or malignant lesion. The treatment is performed through completion total gastrectomy (CTG) with radical lymphadenectomy. Some reports consider this procedure may be associated with higher rates of morbidity and mortality. Objective: to evaluate surgical results and survival after CTG in patients with RGC. Methods: 54 patients who underwent CTG between 2009 and 2019 were included in the study. As a comparison group 215 patients with primary gastric cancer (PGC) who underwent total gastrectomy (TG) in the same period were selected. Results: among the initial characteristics, age (68.0 vs. $60.5 ; p<0.001)$, hemoglobin values $(10.9$ vs. $12.3 ; p<0.001)$ and body mass index ( 22.5 vs. 24.6; $p=0.005$ ) were different between the RGC and PGC groups, respectively. The most frequent postoperative complications were related to pulmonary complications, infection and fistula in both groups. There was a higher incidence of esophagojejunal fistula in the CTG group (14.8\% vs $6.5 \%, p=0.055)$. Perioperative mortality was higher in RGC patients $(9.3 \%$ vs. $5.1 \%)$, but without significance $(p=0.329)$. Hospital length of stay, postoperative complications graded by the Clavien-Dindo classification, mortality at 30 and 90 days were not different between groups. There was no significant difference in disease-free and overall survival between RGC and PGC groups. Conclusion: despite previous reports, surgical results and survival were similar between groups. Higher risk of esophagojejunal fistula must be considered.
\end{abstract}

Keywords: Stomach Neoplasms. Survival Analysis. Postoperative Complications. Gastric Stump.

\section{INTRODUCTION}

G astric cancer (GC) is the fifth most common cancer in the world, persisting as an important global public health issue'. According to its location, GC is usually divided into distal and proximal tumors or even tumors involving the entire organ. However, there is a type of GC that does not fit this classification, which is the gastric stump tumor - or remnant gastric cancer (RGC). It is defined as a tumor that develops five years or later after previous gastrectomy ${ }^{2}$. Its incidence varies between 2 to $6 \%$ among all cases of $\mathrm{GC}^{3,4}$. The RGC can occur in the remnant stomach after previous resection for benign or malignant lesions ${ }^{5}$.

The exact carcinogenic mechanism of RGC is still unknown. Bile reflux of bile from afferent jejunal limb, previous vagotomy and change in the gastric microenvironment may play an important role in this process. These events can lead to metaplasia and dysplasia of gastric mucosa, culminating in the genesis of $R G C^{3,6,7}$. The reported time necessary to turn this remnant inflamed mucosa into a neoplastic epithelium is over 20 years after previous resection for benign disease.

Although there is a recommendation for follow-up after partial gastrectomy, the long period of carcinogenesis after previous resection may discourage patients to maintain a continuous regular monitoring. This may lead to late diagnosis of RGC, with more advanced clinical stages and worse prognosis $3,8,9$.

The surgical treatment for RGC is performed through completion total gastrectomy (CTG) with radical lymphadenectomy. Adhesion to adjacent organs and displacement of anatomical structures are common difficulties during the procedure, turning it longer and more prone to combined repair or resection of adjacent

1 - Instituto do Câncer, Hospital das Clinicas HCFMUSP, Faculdade de Medicina, Universidade de Sao Paulo - São Paulo - SP - Brasil 2 - Universidade Anhembi-Morumbi, Curso de Medicina - São Paulo - SP - Brasil 
organs. Cases in which the first surgery was performed for perforated gastric ulcer also causes the formation of more extensive adhesions. Therefore, higher rates of morbidity and mortality after CTG are reported ${ }^{10}$.

The aim of this study was to evaluate the surgical outcomes and survival of patients after completion total gastrectomy (CTG) compared to patients with primary gastric cancer (PGC) who underwent total gastrectomy (TG).

\section{METHODS}

All patients who underwent CTG for RGC from 2009 to 2019 were selected for this study by searching our prospective database. As a comparison group, patients with primary $\mathrm{GC}(\mathrm{PGC})$ who underwent total gastrectomy with curative intent during the same period were selected. Exclusion criteria were: non-adenocarcinoma histology, gastric resection performed less than 5 years and palliative resections.

Patients were staged preoperatively through abdominal and pelvis computed tomography, endoscopy and laboratory tests. TNM staging was performed according to the TNM $8^{\text {th }}$ edition. Clinical characteristics evaluated included American Society of Anesthesiologists (ASA) classification, Charlson-Deyo Comorbidity Index $(\mathrm{CCl})^{11}$ and laboratory tests. $\mathrm{CCl}$ was considered without inclusion of age and gastric cancer as comorbidity.

Additionally, patients were evaluated for lymph node status according to the "lymph node ratio", as proposed by Deng et al. ${ }^{12}$. Patients were classified into 4 categories based in the following cutoff points: $L R 0=0.1 \%$ $10 \%$ ，LR1 $=10 \%-20 \%$, LR2=20\%-40\%, LR3 $>40 \%$. All cases were operated in a high-volume center by specialist surgeons. The extent of lymph node (LN) dissection, as well as the need for other organ resection during CTG, was established by the operating surgeon in order to achieve a complete $\mathrm{RO}$ resection. The extent of resection and dissected LN stations of the TG group followed the recommendations of the Japanese Gastric Cancer Association guidelines ${ }^{13}$.

Postoperative complications (POC) were graded according to Clavien-Dindo's classification ${ }^{14}$. Major complications were considered as Clavien III-V. Surgical mortality was defined when it occurred within the first
30 days after surgery or during hospital stay after the procedure.

The postoperative follow-up was performed on a quarterly basis in the first year and every 6 months in the following years. Follow-up tests for recurrence detection were performed based on the presence of symptoms. Absence in medical appointments for more than 12 months was considered as loss of follow-up. The study was approved by the hospital ethics committee (NP1586/19) and registered online (www.plataformabrasil.com; CAAE: 2915516.2.0000.0065).

\section{Statistical analysis}

The Chi-square tests were used for categorical variables and t-tests for continuous variables. The association of clinical and surgical variables with the occurrence of major postoperative complications (POC) was analyzed by binary logistic regression analysis, and odds ratios (ORs) with 95\% confidence interval (95\% Cl) were calculated. Survival time, in months, was calculated from the date of surgery until the date of death/ recurrence. Overall survival (OS) and disease-free survival (DFS) were estimated using the method of Kaplan-Meier, and differences in survival were examined using the Log Rank Test. To determine factors associated with DFS and OS, univariate and multivariate Cox proportional hazard regression models were employed. The patients alive were censored at the date of last contact. All tests were twosided and $p<0.05$ was considered statistically significant. Statistical analysis was performed using SPSS software, version 18.0 (SPSS Inc, Chicago, IL).

\section{RESULTS}

During the selected period, 1,157 GC patients were admitted to surgical treatment at our Hospital. Completion total gastrectomy was performed in 54 patients. The comparison group was composed of 215 patients with PGC who underwent TG.

All RGC patients were previously operated by open approach. The mean age of RGC patients at the time of first surgery was 38.8 years (range $19-75.7$ years), and the median interval time between the first and the second surgery was 29.1 years. Gastrojejunostomy 
(Billroth II) was the previous reconstruction in 42 (77.8\%) cases and Roux-en-Y in 12 (22.2\%) cases. Previous gastric resection was due to peptic ulcer and neoplasia in $44(81.5 \%)$ and $10(18.5 \%)$ patients, respectively.
Clinical and surgical characteristics of the CTG and TG groups are summarized in Table 1. Patients in CTG group were significantly older $(p<0.001)$, had lower BMI $(p=0.005)$ and hemoglobin levels $(p<0.001)$.

Table 1. Clinical characteristics of total gastrectomy and completion total gastrectomy patients.

\begin{tabular}{|c|c|c|c|}
\hline Variables & $\begin{array}{c}\text { Total gastrectomy } \\
n=215(\%)\end{array}$ & $\begin{array}{c}\text { Completion TG } \\
n=54(\%)\end{array}$ & $\mathrm{p}$ \\
\hline Sex & & & 0.092 \\
\hline Female & $69(32.1)$ & $11(20.4)$ & \\
\hline Male & $146(67.9)$ & $43(79.6)$ & \\
\hline Age (years & & & $<0.001$ \\
\hline Mean (SD) & $60.5(13.1)$ & $68.0(8.7)$ & \\
\hline Body Mass Index (Kg/m²) & & & 0.005 \\
\hline Mean (SD) & $24.6(4.8)$ & $22.5(4.0)$ & \\
\hline Hemoglobin (g/dL) & & & $<0.001$ \\
\hline Média (DP) & $12.3(2.2)$ & $10.9(2.1)$ & \\
\hline Albumin (g/dL) & & & 0.432 \\
\hline Mean (SD) & $4.1(2.2)$ & $3.9(0.5)$ & \\
\hline Neutrophil lymphocyte ratio (NLR) & & & 0.939 \\
\hline Mean (SD) & $2.94(2.89)$ & $2.97(2.20)$ & \\
\hline Charlson-Deyo Comorbidity Index (CCI) & & & 0.806 \\
\hline 0 & $151(70.2)$ & $37(68.5)$ & \\
\hline$\geq 1$ & $64(29.8)$ & $17(31.5)$ & \\
\hline ASA (American Society of Anesthesiologists) & & & 0.715 \\
\hline | / || & $158(73.5)$ & $41(75.9)$ & \\
\hline III / IV & $57(26.5)$ & $13(24.1)$ & \\
\hline Surgical approach & & & 0.991 \\
\hline Open & $191(88.8)$ & $48(88.9)$ & \\
\hline Laparoscopic & $24(11.2)$ & $6(11.1)$ & \\
\hline
\end{tabular}

Regarding the pathological characteristics of both groups, presence of venous invasion, lower rate of LN metastasis ( $\mathrm{pN}$ ) and less advanced pTNM stage were associated to CTG. CTG group had a significantly lower number of retrieved LN than TG group $(p<0.001)$. There was no difference in $L N$ ratio $(L R)$ between groups (Table 2).

A descriptive list of all POC is shown in Table 3. Grade $\mid / / I$ complications were more common and occurred in $24.2 \%$ and $31.5 \%$ of all TG and CTG cases respectively. Surgical complications were more related to pulmonary complications, infection and fistula formations.

There was no difference in the occurrence of
POC between the groups. Esophagojejunal fistula was more common after CTG (14.8\% vs 6.5\%) although not statistically significant $(p=0.055)$. Perioperative mortality was higher in CTG (9.3\% vs $5.1 \%$ ) but without significance $(p=0.329)$. Also, no difference was observed in 30 and 90-day mortality between TG and CTG groups. Chemotherapy was performed more frequently in TG patients $(p<0.001)$ (Table 4).

To assess the potential risk factors for major POC, a multivariate analysis including only preoperative variables, in addition to the CTG and TG, was performed. In the multivariate model, only ASA III/IV and low BMI were identified as independent risk factors for major POC (Table 5). 
Table 2. Pathological characteristics of total gastrectomy and completion total gastrectomy patients.

\begin{tabular}{|c|c|c|c|}
\hline Variables & $\begin{array}{c}\text { Total gastrectomy } \\
n=215(\%)\end{array}$ & $\begin{array}{c}\text { Completion TG } \\
n=54(\%)\end{array}$ & $p$ \\
\hline Tumor size & & & 0.140 \\
\hline Mean (SD) & $5.6(3.5)$ & $4.8(3.2)$ & \\
\hline Lauren type* & & & 0.101 \\
\hline Intestinal & $111(52.4)$ & $35(64.8)$ & \\
\hline Diffuse/mixed & $101(47.6)$ & $19(35.2)$ & \\
\hline Grade of differentiation* & & & 0.071 \\
\hline $\mathrm{G} 1 / \mathrm{G} 2$ & $85(40.1)$ & $29(53.7)$ & \\
\hline G3 & $127(59.9)$ & $25(46.3)$ & \\
\hline Lymphatic invasion & & & 0.258 \\
\hline No & $97(45.1)$ & $29(53.7)$ & \\
\hline Yes & $118(54.9)$ & $25(46.3)$ & \\
\hline Venous invasion & & & 0.017 \\
\hline No & $134(62.3)$ & $43(79.6)$ & \\
\hline Yes & $81(37.7)$ & $11(20.4)$ & \\
\hline Perineural Invasion & & & 0.370 \\
\hline No & $89(41.4)$ & $26(48.1)$ & \\
\hline Yes & $126(58.6)$ & $28(51.9)$ & \\
\hline pT & & & 0.544 \\
\hline $\mathrm{pT} 1 / \mathrm{T} 2$ & $78(36.3)$ & $22(40.7)$ & \\
\hline pT3 / T4 & $137(63.7)$ & $32(59.3)$ & \\
\hline Number of ressected LNs & & & $<0.001$ \\
\hline Mean (SD) & $43.8(20.6)$ & $22.3(14.4)$ & \\
\hline LNM & & & 0.010 \\
\hline pNO & $78(36.3)$ & $30(55.6)$ & \\
\hline $\mathrm{pN}+$ & $137(63.7)$ & $24(44.4)$ & \\
\hline Lymph Node Ratio & & & 0.414 \\
\hline LRO & $124(57.7)$ & $35(64.8)$ & \\
\hline LR1 & $35(16.3)$ & $10(18.5)$ & \\
\hline LR2 & $21(9.8)$ & $5(9.3)$ & \\
\hline LR3 & $35(16.3)$ & $4(7.4)$ & \\
\hline pTNM & & & 0.041 \\
\hline | / || & $102(47.4)$ & $34(63)$ & \\
\hline III / IV & $113(53.6)$ & $20(37)$ & \\
\hline
\end{tabular}

Table 3. List of all complications of total gastrectomy and completion total gastrectomy patients.

\begin{tabular}{|c|c|c|c|c|}
\hline \multirow[b]{2}{*}{ Postoperative complication/ Grade } & \multicolumn{2}{|c|}{ TG * } & \multicolumn{2}{|c|}{ Completion TG** } \\
\hline & I/II & III / IV / V & I/II & III / IV / V \\
\hline \multicolumn{5}{|l|}{ Cardiac } \\
\hline Angina/Myocardial infarction & 1 & 1 & 2 & \\
\hline \multicolumn{5}{|l|}{ Arrhythmia } \\
\hline \multicolumn{5}{|l|}{ Pulmonay } \\
\hline Acute respiratory distress syndrome & 1 & & 1 & 1 \\
\hline Pneumonia & 5 & 4 & & 2 \\
\hline Pleural effusion/Pneumo/Hemothorax & & 3 & & \\
\hline
\end{tabular}




\section{Thromboembolic}

Pulmonary embolism

Other

Infection

Superficial Surgical site infection (SSI)

Deep SSI

Organ/Space SSI

Central IV line infection

Bacteremia/Generalized sepsis

Urinary tract infection

Other infections requiring antibiotics

Gastrointestinal

Abdominal wall Dehiscence

Delayed gastric emptying/ileus

Diarrhea

Intra/Extra luminal bleeding

Neurologic

Delirium tremens

Other

Fistula

Biliar

Enteric/Colonic

Chylous

Duodenal Stump

Esophagojejunal

Pancreatic
2

11

2

1

3

1

2

2

3

1

4

1

1

2

1

1

$\begin{array}{lll}6 & 2 & 2\end{array}$

2

$1 \quad 3 \quad 1$

$\begin{array}{lll}5 & 9 & 3\end{array}$

9

$52(24.2)$
1

1
36 (16.7)

$17(31.5)$

Total (\%)

$13(24.1)$

* Six patients in the TG group had more than one POC with a higher rates: 1 case with Clavien III; and 5 cases with Clavien II.

** Five patients in the TCG group group had more than one POC with a higher degree: 4 cases with Clavien II; and 1 case with Clavien III.

\# in relation to the total number of patients in each group (TG $=215$ and TCG $=54$ ).

Table 4. Outcomes of total gastrectomy and completion total gastrectomy patients.

\begin{tabular}{|c|c|c|c|}
\hline Variables & $\begin{array}{c}\text { Total gastrectomy } \\
\mathrm{n}=215(\%)\end{array}$ & $\begin{array}{c}\text { Completion TG } \\
n=54(\%) \\
\end{array}$ & $p$ \\
\hline Hospital length of stay & & & 0.062 \\
\hline Mean (SD) & $16.0(10.1)$ & $20.5(16.8)$ & \\
\hline Type of Postoperative complication & & & 0.659 \\
\hline None & $132(61.4)$ & $30(55.6)$ & \\
\hline Clinical & $21(9.8)$ & $5(9.3)$ & \\
\hline Surgical & $62(28.8)$ & $19(35.2)$ & \\
\hline Grade of Postoperative complication * & & & 0.304 \\
\hline $0-1-\|$ & $180(83.7)$ & $42(77.8)$ & \\
\hline III - IV - V & $35(16.3)$ & $12(22.2)$ & \\
\hline Esophagojejunal fistula & & & 0.055 \\
\hline No & $201(93.5)$ & $46(85.2)$ & \\
\hline Yes & $14(6.5)$ & $8(14.8)$ & \\
\hline
\end{tabular}




\begin{tabular}{|c|c|c|c|}
\hline 30-day Mortality & & & 1.0 \\
\hline No & 207 (96.3) & 52 (96.3) & \\
\hline Yes & $8(3.7)$ & $2(3.7)$ & \\
\hline 90-day Mortality & & & 0.151 \\
\hline No & $201(93.5)$ & $47(87)$ & \\
\hline Yes & $14(6.5)$ & $7(13)$ & \\
\hline Chemotherapy & & & $<0.001$ \\
\hline No & $81(37.7)$ & $40(74.1)$ & \\
\hline Yes & $134(62.3)$ & $14(25.9)$ & \\
\hline Recurrence & & & 0.931 \\
\hline No & $142(66)$ & $36(66.7)$ & \\
\hline Yes & $73(34)$ & $18(33.3)$ & \\
\hline
\end{tabular}

Table 5. Univariate and multivariate analyses for major postoperative complications.

\begin{tabular}{|c|c|c|c|c|c|c|}
\hline \multirow{2}{*}{$\begin{array}{l}\text { Major Complication } \\
\text { Variables }\end{array}$} & \multicolumn{2}{|c|}{ Univariate } & \multirow[b]{2}{*}{$\mathrm{p}$} & \multicolumn{2}{|c|}{ Multivariate } & \multirow[b]{2}{*}{$\mathrm{p}$} \\
\hline & OR & $95 \% \mathrm{Cl}$ & & OR & $95 \% \mathrm{Cl}$ & \\
\hline Female (vs male) & 1.48 & $0.71-3.07$ & 0.298 & - & - & - \\
\hline Age $\geq 65$ (vs $<65$ years) & 1.30 & $0.69-2.43$ & 0.419 & - & - & - \\
\hline $\mathrm{BMI}<18.5$ (vs $\geq 18.5)$ & 2.81 & $1.21-6.49$ & 0.016 & 3.19 & $1.35-7.53$ & 0.008 \\
\hline ASA III/IV (vs I/II) & 1.03 & $1.04-3.95$ & 0.037 & 2.33 & $1.17-4.63$ & 0.016 \\
\hline $\mathrm{CCl} \geq 1$ (vs 0 ) & 1.57 & $0.81-3.02$ & 0.180 & - & - & - \\
\hline $\mathrm{Hb}<13(\mathrm{vs} \geq 13)$ & 0.97 & $0.51-1.84$ & 0.920 & - & - & - \\
\hline$N L R \geq 2.5(v s<2.5)$ & 0.99 & $0.52-1.87$ & 0.990 & - & - & - \\
\hline Completion TG (vs TG) & 1.47 & $0.70-3.07$ & 0.306 & - & - & - \\
\hline
\end{tabular}

OR: Odds ratio.

\section{Survival analysis}

After a mean follow-up of 34 months, 91 patients had disease recurrence and 121 died. The median OS for the entire cohort was 54 months. Kaplan-Meier curves are demonstrated in Figure 1. The DFS curves were similar between CTG and TG patients $(p=0.986)$. Considering the OS, no significant difference was observed between both groups $(p=0.462)$. The median OS for TG and CTG was 56.3 and 41.4 months, respectively.
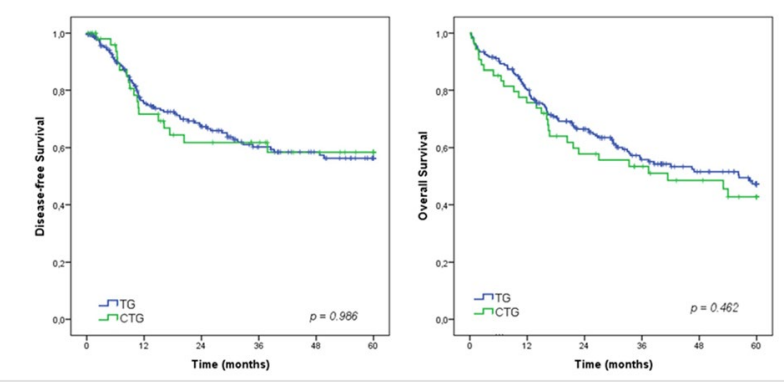

Figure 1. Disease-free survival and overall survival of total gastrectomy and completion total gastrectomy patients.

\section{DISCUSSION}

In the present study, we analyzed the surgical outcomes of RGC patients who underwent CTG and compared with PGC patients. Patients with RGC were older, with lower BMI and lower hemoglobin levels, but they were not diagnosed in more advanced stages. The most frequent POC were pulmonary complications, infection and fistula in both groups. However, the severity of complications and survival analysis did not differ between CTG and PGC patients. Of notice, there was a higher incidence of esophagojejunal fistula in the CTG group ( $14.8 \%$ vs $6.5 \%, p=0.055)$.

RGC can occur after gastric resection for peptic disease or neoplasia. The introduction of $\mathrm{H2}$ receptor antagonists and proton pump inhibitor in the 1980s dramatically reduced the number of gastric resections due to peptic disease ${ }^{15}$. However, as the period of development of the RGC is long and due to the widespread indication of gastric resection in our country in the past, we still find a predominance of 
previous resections due to peptic disease in the group of RGC analyzed. On the other hand, the improvement in the results of GC treatment has increased the survival of patients who underwent gastric resection, also increasing the population susceptible to the development of a new neoplasm in the gastric remnant ${ }^{4}$. Therefore, a shift in this proportion benign/malignant related to the previous indications of gastric resection is expected in the future. Gastric resections for the treatment of neoplasms include lymphadenectomy. Lymphadenectomy, especially D2, causes the formation of more extensive adhesions by increasing the dissection area. Performing lymphadenectomy also increases the possibility of complications in the first procedure that can hinder CTG.

We found that Billroth II (BII) was the most performed reconstruction method after the previous gastric resection, which is consistent with the higher frequency of previous resection due to peptic disease. Traditionally, resections due to benign disease are reconstructed by $\mathrm{Bll}$ or $\mathrm{Bl}^{16}$. This type of reconstruction implies the performance of only one anastomosis (gastrojejunal), minimizing the risk of fistulas, which is a major concern, especially if previous surgery was performed in an emergency scenario. There is a great debate in the literature if the association of RGC with BII reconstruction reflects only the habit of reconstruction or whether it is actually associated with a cause-effect relationship in the remnant carcinogenesis 3,6,17-20. $^{3}$.

We found some differences between groups related to the baseline characteristics. Older age was related to CTG group, which is compatible with the long period of carcinogenesis after previous resection. The absorption of most dietary iron occurs in the duodenum and proximal jejunum. Both reconstructions, BII and Roux-en-Y, derive precisely this segment of intestinal transit, which justifies the higher occurrence of lower hemoglobin values in the RGC group. The duodenojejunal exclusion may also be related to the lower BMI level of RGC in association with reducing the production of gastrointestinal hormone ghrelin in the stomach, responsible for the appetite ${ }^{8,21}$. It must be remembered that final clinical stages, an important confounding variable related to $\mathrm{BMI}$ and Hemoglobin levels, associated earlier stages I/II to RGC patients, contrary to some previous reports 22,23 .
In both groups the most common complications were pulmonary, infectious and related to the formation of fistulas. In addition, there was no difference between groups related to severity, frequency and type of complications. Other short-term surgical outcomes measures as length of hospital stay, 30-day mortality and even the later 90-day mortality were also similar. Also, the analysis of the potential risk factors for POC identified only ASA III/IV and low BMI as independent risk factors for the entire cohort - CTG or TG were not associated with the risk of $\mathrm{POC}$

The only postoperative outcome that statistically differs between groups was the rate of patients receiving adjuvant chemotherapy. Surgical complications may prevent patients to return to intended oncological treatment (RIOT) or delay treatment to a point when referrals no longer provide benefits ${ }^{24}$. However, we believe that in our series, the lower frequency of adjuvant treatment was influenced by the most advanced age and the lowest incidence of LN metastasis in CTG group patients, rather than surgical complications ${ }^{25}$.

A specific analysis of esophagojejunal fistulas was planned based on the previous report of its association with the performance of $\mathrm{CTG}^{26}$. In fact, we verified a higher incidence of esophagojejunal fistulas in the CTG group (14.8\% vs $6.5 \%$ ) which, despite not reaching the value determined for statistical significance, corroborates our previous report and perception of clinical practice.

Eventually, long-term outcomes DFS and OS were also similar between groups. These results may have been influenced by some unfavorable characteristics associated to TG groups, as the presence of tumors with poorly differentiated histology, venous invasion and positive LN. On the other hand, CTG was associated with older age and lower administration of adjuvant chemotherapy. Despite these differences in important covariates that may influence the survival analysis, we considered that there was no confirmation of the hypothesis usually described that associates a worse prognosis to patients with $\mathrm{RGC}^{5,9,20,22,27,28}$.

The present study had some limitations. Due to its retrospective design, we were not able to report data about the clinical characteristics related to the first gastric resection. Whether it was an elective or 
emergency procedure, surgical complications and other characteristics could not be analyzed and may have influenced the results of the second procedure. The low number of patients who underwent previous resection for neoplasia made impossible to analyze the impact of previous lymphadenectomy as a factor for complications of CTG. A common concern in reports related to RGC is the uncertainty regarding TNM staging, mainly related to $\mathrm{N}$ category, because patients with previous resection would obviously have a lower number of $L N$ resected during CTG. Thus, the exact number of lymph nodes that must be removed to avoid under-staging remains under discussion, as well as which stations must be removed during lymphadenectomy ${ }^{29,30}$. Apparently, it did not impact in our survival analysis and we even included the LN ratio to address this limitation in the analysis ${ }^{12,31,32}$.

Due to its rarity and diversity, the characteristics of RGC, as well as the prognostic factors and survival related to this type of disease, remain in discussion and are difficult to report. In the present study, we were able to report a distinguish number of 54 RGC patients treated at a single western institution. This ensures standardization of surgical and perioperative treatment, minimizing this important bias. Outcome measures analyzed included the perioperative period, 30 and 90day mortality and the long-term DFS/OS, allowing a broad view of surgical and oncological results of RGC treatment. As gastric resection for benign disease was commonly performed until the late 1980s and created a large cohort of patients with gastric remnant at risk of RGC. Therefore, surgeons must be aware of these characteristics to perform the best clinical practices.

\section{CONCLUSIONS}

Patients who underwent completion total gastrectomy for RGC had same frequency and severity of clinical and surgical complications compared to total gastrectomy patients with primary GC. The long-term DFS and OS also did not differ between CTG and TG groups. However, a higher risk of esophagojejunal fistula must be considered in CTG.

\title{
R E S U M O
}

\begin{abstract}
Antecedentes: o câncer do coto ou remanescente gástrico (CRG) se desenvolve cinco anos ou mais após a ressecção gástrica por lesão benigna ou maligna. O tratamento é realizado através da gastrectomia total complementar (GTC) com linfadenectomia. Alguns relatos consideram que esse procedimento pode estar associado a maiores taxas de morbimortalidade. Objetivo: avaliar os resultados cirúrgicos e a sobrevida após GTC em pacientes com CRG. Métodos: 54 pacientes submetidos a GTC entre 2009 e 2019 foram incluídos no estudo. Como grupo de comparação, foram selecionados 215 pacientes com câncer gástrico primário (CGP) submetidos à gastrectomia total (GT) no mesmo período. Resultados: dentre as características iniciais, a idade média $(68,0$ vs. 60,$5 ; p<0,001)$, os valores de hemoglobina (10,9 vs. 12,$3 ; p<0,001)$ e o índice de massa corporal $(22,5$ vs. 24,$6 ; p=0,005)$ diferiram entre os grupos CRG e CGP, respectivamente. As complicações pós-operatórias mais frequentes foram pulmonares, infecciosas e fístulas nos dois grupos. Houve maior incidência de fístula esofagojejunal no grupo GTC $(14,8 \%$ vs $6,5 \%, p=0,055)$. A mortalidade perioperatória foi maior nos pacientes com CRG $(9,3 \%$ vs. $5,1 \%)$, mas sem significância $(p=0,329)$. O tempo de internação hospitalar, complicações pós-operatórias (Clavien-Dindo), mortalidade aos 30 e 90 dias não foram diferentes entre os grupos. Não houve diferença significativa na sobrevida livre de doença e global entre os grupos CRG e CGP. Conclusão: apesar dos relatos anteriores, os resultados cirúrgicos e a sobrevida foram semelhantes entre os grupos. Maior risco de fístula esofagojejunal dever ser considerado.
\end{abstract}

Palavras chave: Neoplasias Gástricas. Análise de Sobrevida. Complicações Pós-Operatórias. Coto Gástrico.

\section{REFERENCES}

1. Ferlay J, Colombet M, Soerjomataram I, Dyba T, Randi $G$, Bettio $M$, et al. Cancer incidence and mortality patterns in Europe: Estimates for 40 countries and 25 major cancers in 2018. Eur J Cancer. 2018;103:35687.

2. Balfour DC. Factors influencing the life expectancy of patients operated on for gastric ulcer. Ann Surg. 1922;76(3):405-8.

3. Ohira M, Toyokawa T, Sakurai K, Kubo N, Tanaka H,
Muguruma K, et al. Current status in remnant gastric cancer after distal gastrectomy. World J Gastroenterol. 2016;22(8):2424-33.

4. Ramos MFKP, Pereira MA, Yagi OK, Dias AR, Charruf $A Z$, Oliveira RJ, et al. Surgical treatment of gastric cancer: a 10-year experience in a high-volume university hospital. Clinics (Sao Paulo). 2018;73(suppl 1):e543s.

5. Irino T, Hiki N, Ohashi M, Nunobe S, Tokunaga M, Sano T, et al. Characteristics of gastric stump cancer: A single hospital retrospective analysis of 262 patients. 
Surgery. 2016;159(6):1539-47.

6. Mezhir JJ, Gonen M, Ammori JB, Strong VE, Brennan MF, Coit DG. Treatment and outcome of patients with gastric remnant cancer after resection for peptic ulcer disease. Ann Surg Oncol. 2011;18(3):670-6.

7. Tanigawa N, Nomura E, Lee SW, Kaminishi M, Sugiyama $M$, Aikou $T$, et al. Current state of gastric stump carcinoma in Japan: based on the results of a nationwide survey. World J Surg. 2010;34(7):1540-7.

8. Di Leo A, Pedrazzani C, Bencivenga M, Coniglio A, Rosa F, Morgani P, et al. Gastric stump cancer after distal gastrectomy for benign disease: clinicopathological features and surgical outcomes. Ann Surg Oncol. 2014;21(8):2594-600.

9. Huang $H$, Wang W, Chen Z, Jin JJ, Long ZW, Cai $\mathrm{H}$, et al. Prognostic factors and survival in patients with gastric stump cancer. World J Gastroenterol. 2015;21(6):1865-71.

10. Kwon IG, Cho I, Choi YY, Hyung WJ, Kim CB, Noh $\mathrm{SH}$. Risk factors for complications during surgical treatment of remnant gastric cancer. Gastric Cancer. 2015;18(2):390-6.

11. Charlson $M E$, Pompei $P$, Ales $K L$, MacKenzie CR. A new method of classifying prognostic comorbidity in longitudinal studies: development and validation. J Chronic Dis. 1987;40(5):373-83.

12. Deng J, Liang $H$, Wang $D$, Sun $D$, Ding $X$, Pan $Y$, et al. Enhancement the prediction of postoperative survival in gastric cancer by combining the negative lymph node count with ratio between positive and examined lymph nodes. Ann Surg Oncol. 2010;17(4):1043-51.

13. Japanese Gastric Cancer Association. Japanese gastric cancer treatment guidelines 2018 (5th edition). Gastric Cancer. 2020. doi: 10.1007/s10120-02001042-y.

14. Dindo D, Demartines N, Clavien PA. Classification of surgical complications: a new proposal with evaluation in a cohort of 6336 patients and results of a survey. Ann Surg. 2004;240(2):205-13.

15. Takeno S, Hashimoto T, Maki K, Shibata R, Shiwaku $H$, Yamana l, et al. Gastric cancer arising from the remnant stomach after distal gastrectomy: a review. World J Gastroenterol. 2014;20(38):13734-40.

16. Fukuhara $K$, Osugi $H$, Takada N, Takemura M, Higashino $M$, Kinoshita $\mathrm{H}$. Reconstructive procedure after distal gastrectomy for gastric cancer that best prevents duodenogastroesophageal reflux. World J Surg. 2002;26(12):1452-7.

17. Son SY, Kong SH, Ahn HS, Park YS, Ahn SH, Suh YS, et al. The value of $\mathrm{N}$ staging with the positive lymph node ratio, and splenectomy, for remnant gastric cancer: A multicenter retrospective study. J Surg Oncol. 2017;116(7):884-93.

18. Kondo K. Duodenogastric reflux and gastric stump carcinoma. Gastric Cancer. 2002;5(1):16-22.

19. Lagergren J, Lindam A, Mason RM. Gastric stump cancer after distal gastrectomy for benign gastric ulcer in a population-based study. Int J Cancer. 2012;131(6):E1048-52.

20. Mak TK, Guan B, Peng J, Chong TH, Wang C, Huang S, et al. Prevalence and characteristic of gastric remnant cancer-A systematic review and meta-analysis. Asian J Surg. 2020;S1015-9584(20)30090-7.

21. Goto H, Kanaji S, Otsubo D, Oshikiri T, Yamamoto $M$, Nakamura $T$, et al. Comparison of total versus subtotal gastrectomy for remnant gastric cancer. Langenbecks Arch Surg. 2019;404(6):753-60.

22. Komatsu S, Ichikawa D, Okamoto K, Ikoma D, Tsujiura M, Nishimura $Y$, et al. Progression of remnant gastric cancer is associated with duration of follow-up following distal gastrectomy. World J Gastroenterol. 2012;18(22):2832-6.

23. Imamura $T$, Komatsu S, Ichikawa D, Kosuga $T$, Okamoto K, Konishi $\mathrm{H}$, et al. Reconstruction method as an independent risk factor for the postoperative decrease in hemoglobin in stage I gastric cancer. J Gastroenterol Hepatol. 2016;31(5):959-64.

24. Ramos MFKP, de Castria TB, Pereira MA, Dias AR, Antonacio FF, Zilberstein $B$, et al. Return to Intended Oncologic Treatment (RIOT) in Resected Gastric Cancer Patients. J Gastrointest Surg. 2020;24(1):1927.

25. Costa-Pinho A, Pinto-de-Sousa J, Barbosa J, CostaMaia J. Gastric stump cancer: more than just another proximal gastric cancer and demanding a more suitable TNM staging system. Biomed Res Int. 2013;2013:781896.

26. Barchi LC, Ramos MFKP, Pereira MA, Dias AR, Ribeiro-Júnior $U$, Zilberstein $B$, et al. Esophagojejunal anastomotic fistula: a major issue after radical total 
gastrectomy. Updates Surg. 2019;71(3):429-38.

27. Li F, Zhang R, Liang $H$, Quan J, Liu H, Zhang $H$. Gastric remnant cancer patients had a better prognosis than upper-third gastric cancer patients in a case-control study after surgical treatment. Tumori. 2013;99(4):510-5.

28. Wang $Y$, Huang $C M$, Wang JB, Zheng $\mathrm{CH}$, Li P, Xie JW, et al. Survival and surgical outcomes of cardiac cancer of the remnant stomach in comparison with primary cardiac cancer. World J Surg Oncol. 2014;12:21.

29. Watanabe $M$, Kinoshita $T$, Morita $S$, Yura $M$, Tokunaga M, Otsuki $S$, et al. Clinical impact of splenic hilar dissection with splenectomy for gastric stump cancer. Eur J Surg Oncol. 2019;45(8):150510. Erratum in: Corrigendum to " Clinical impact of splenic hilar dissection with splenectomy for gastric stump cancer " [Eur J Surg Oncol 45/8 (2019) 15051510]. Watanabe $M$, Kinoshita T, Morita S, Yura M, Tokunaga M, Otsuki S, Yamagata Y, Kaito A, Yoshikawa T, Katai H. Eur J Surg Oncol. 2020;46(10 Pt A):1971.

Received in: 02/07/2020

Accepted for publication: 28/07/2020

Conflict of interest: no.

Funding source: none.
30. Katai H, Ishikawa $T$, Akazawa K, Fukagawa $T$, Isobe Y, Miyashiro I, Oda I, Tsujitani S, Ono H, Tanabe S, Nunobe S, Suzuki S, Kakeji Y; Registration Committee of the Japanese Gastric Cancer Association. Optimal extent of lymph node dissection for remnant advanced gastric carcinoma after distal gastrectomy: a retrospective analysis of more than 3000 patients from the nationwide registry of the Japanese Gastric Cancer Association. Gastric Cancer. 2020 May 17. doi: 10.1007/s10120-020-01081-5. Online ahead of print.

31. Iguchi K, Kunisaki C, Sato S, Tanaka Y, Miyamoto H, Kosaka T, et al. Evaluation of Optimal Lymph Node Dissection in Remnant Gastric Cancer Based on Initial Distal Gastrectomy. Anticancer Res. 2018;38(3):167783.

32. Nakagawa M, Choi YY, An JY, Hong JH, Kim JW, $\mathrm{Kim} \mathrm{HI}$, et al. Staging for Remnant Gastric Cancer: The Metastatic Lymph Node Ratio vs. the UICC 7th Edition System. Ann Surg Oncol. 2016;23(13):432231.

\section{Mailing address:}

Marcus Fernando Kodama Pertille Ramos

E-mail: marcus.kodama@hc.fm.usp.br

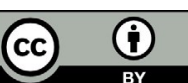

